\title{
Viso: Cadernos de estética aplicada
}

Revista eletrônica de estética

ISSN 1981-4062

$N^{0} 26$, jan-jun/2020

http://www.revistaviso.com.br/
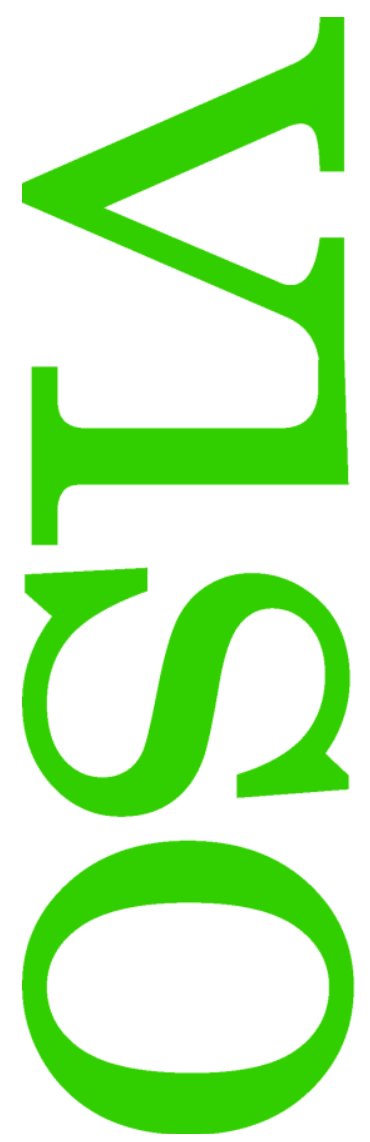

\section{A Bienal de Arte de Curitiba e o circuito artístico local \\ Vinicius Figueiredo}




\section{RESUMO}

\section{A Bienal de Arte de Curitiba e o circuito artístico local}

O artigo discute a relação entre o circuito artístico curitibano e a Bienal de Arte de Curitiba, que se encontra em sua $14^{\text {a }}$ edição. Para fazê-lo, retomo, em linhas muito gerais, a formação de um circuito artístico moderno no Brasil e passo ao exame de como este circuito se estruturou em Curitiba nas décadas de 60/90. Em seguida, aponto as características da Bienal de Artes de Curitiba e arrisco comentar como tem sido a relação do evento com o circuito local.

Palavras-chave

Bienal de Arte de Curitiba; circuito artístico; Mostra de Gravura de Curitiba; diplomacia cultural

\section{ABSTRACT}

\section{The Biennial of Art of Curitiba and the Artistic Local Circuit}

The article discusses the relationship between the Curitiba artistic circuit and the "Curitiba Biennial", which is in its 14th edition. In order to do so, I will return in general to the formation of modern artistic circuit in Brazil and then I pass to the discussion about how this modern circuit was structured in Curitiba in the 1960s/90s. Next, I point out the characteristics of the Bienal de Artes de Curitiba and examine the relationship between the exposition and the local circuit.

Keywords

Curitiba Biennial; artistic circuit; Mostra de Gravura de Curitiba; cultural diplomacy 
FIGUEIREDO, Vinicius. "A Bienal de Arte de Curitiba e o circuito artístico local". Viso: Cadernos de estética aplicada, v. 14, n² 26 (jan-jun/2020), p. 206-230.

Aprovado: 10.03.2020. Publicado: 04.07.2020.

(C) 2020 Vinicius Figueiredo. Esse documento é distribuído nos termos da licença Creative Commons Atribuição-NãoComercial 4.0 Internacional (CC-BY-NC), que permite, exceto para fins comerciais, copiar e redistribuir o material em qualquer formato ou meio, bem como remixá-lo, transformá-lo ou criar a partir dele, desde que seja dado o devido crédito e indicada a licença sob a qual ele foi originalmente publicado.

Licença: $\underline{\text { http://creativecommons.org/licenses/by-nc/4.0/deed.pt_BR }}$

Accepted: 10.03.2020. Published: 04.07.2020.

(C) 2020 Vinicius Figueiredo. This document is distributed under the terms of a Creative Commons Attribution-NonCommercial 4.0 International license (CC-BY-NC) which allows, except for commercial purposes, to copy and redistribute the material in any medium or format and to remix, transform, and build upon the material, provided the original work is properly cited and states its license.

License: http://creativecommons.org/licenses/by-nc/4.0/ 


\section{Bienal de Arte de Curitiba: peculiaridades iniciais}

Falar da Bienal de Arte de Curitiba requer, de partida, ter em mente algumas peculiaridades. A primeira reside no histórico sui generis do evento, que nem sempre se realizou, como sugere o nome, de dois em dois anos. Mas isso não é tudo. Sua primeira edição foi realizada em 2007. Mesmo que ele tivesse sido anual, 2019 deveria corresponder à $12^{\mathrm{a}}$ edição, e não à $14^{\mathrm{a}}$, quando se comemoraram vinte e cinco anos de sua existência.

Há uma explicação para isso. Entre 1993 e 2005, foram realizadas oito edições da "Mostra VentoSul de Artes Visuais". Em 2009, o evento passou a ser chamado de "Bienal VentoSul" e, em 2011, de "Bienal Internacional de Curitiba". Esta última incorporou em sua história as edições da "Bienal VentoSul", além de ter tido edições anuais, ampliando assim o número de edições.

Certos elementos estão presentes desde o início. Primeiro, há o idealizador e diretor do evento, Luiz Ernesto Meyer Pereira, ligado ao Instituto de Artes do Paraná (IAP), fundado em 2002. Discerne-se também certa identidade curatorial, como sugere a presença constante, no corpo dos curadores principais, de Tício Escobar. Também a forma de financiamento foi, essencialmente, baseada em parcerias com órgãos do Estado e em recursos obtidos por isenção fiscal via Lei Rouanet. A despeito de alguns contratempos, o evento teve uma trajetória de expansão recorrente. Cresceram as parcerias institucionais e o número de artistas e de público, assim como o de países representados. A última edição, inaugurada em setembro de 2019 e que se encerrou em março de 2020 reuniu mais de 400 artistas, com exposições em aparelhos culturais diversos, não só em Curitiba.

0 ponto que me interessa discutir é a relação entre um evento dessa magnitude e o campo artístico local. A resposta espontânea seria de que só pode ser uma relação positiva. Afinal, a Bienal é hoje o acontecimento de maior visibilidade na 
cena das artes plásticas curitibana e paranaense e se compara com as megaexposições de outras partes do mundo. Basta folhear o livro de mais de mil páginas em que foram reunidas as edições dos últimos vinte e cinco anos para constatar a diversidade e representatividade de artistas que a Bienal trouxe para a cidade e que, em sua versão expandida, levou para outras regiões do Brasil e fora dele. Além de combinar artistas consagrados com quem está começando, é ocasião para o grande público ter ideia do que se passa no exterior. Os museus locais são prestigiados, o número de visitantes cresce a cada edição. No entanto, a pergunta permanece: de que modo a Bienal incide sobre o campo artístico local e nacional? A fim de ensaiar uma resposta, recapitulemos, em linhas muito gerais, o quadro de fundo - aquele no qual transcorreu a constituição do campo artístico moderno no país. Apesar dos riscos de simplificação, fazê-lo será útil para avaliar o significado da Bienal de Arte de Curitiba para as artes visuais na cidade de Curitiba e no estado do Paraná.

\section{0 circuito artístico e sua configuração moderna no Brasil}

"Circuito artístico" é o circuito formado por artistas, instituições, crítica e público. No Brasil, costuma-se datar a instituição de um circuito artístico moderno nos anos de 1920. 0 livro recém lançado de Ruy Castro, Metrópole à beira-mar - 0 Rio moderno dos anos 20 (2019), além de seus méritos intrínsecos, presta-se como advertência quanto à necessidade permanente de rever a ideia conforme a qual o ingresso do Brasil em águas modernas se deu com a Semana de Arte Moderna de 1922. Mas mesmo que se queira ater-se a São Paulo, há motivos para relativizar certa visão triunfalista que ainda prevalece sobre os modernistas paulistanos. Tadeu Chiarelli observou que Monteiro Lobato (1882-1948), cujo ataque a Anita Malfatti (1889-1964) motivou o contra-ataque de Mario de Andrade, não era partidário dos acadêmicos; ao contrário, defendia um naturalismo que via como mais apropriado para retratar aqueles mesmos aspectos nacionais cuja expressão o grupo de 22 terminou reivindicando. Através 
dessa revisão historiográfica, a Semana de Arte Moderna aparece sob uma faceta menos heroica. 0 Modernismo de 22 teria representado, na verdade, "a ampliação de um debate artístico já instaurado na cidade nos anos que antecederam a Semana". ${ }^{1}$ o circuito moderno não teria surgido ex nihilo, mas sido precedido por uma "cena artística" pautada por escolhas poéticas, informada por textos críticos que circulavam n' 0 Estado de São Paulo e na Revista Brasil, em sintonia com segmentos da elite paulistana empenhados em fomentar as artes e a cultura. Quais seriam as poéticas mais aptas a levar a cabo esse projeto era, aparentemente, uma questão secundária. ${ }^{2}$ Os modernistas paulistas souberam articular-se para convencer determinados segmentos da burguesia local a apostar no interesse e alcance de suas propostas.

Seja como for, a Semana de 22 logrou êxito em propagandear o modernismo, preparando a hegemonia das poéticas modernas na cultura brasileira dos anos 30 e 40 do século passado. Não foi uma coexistência pacífica. Nas artes plásticas desse período, coexistiram direções por vezes complementares, por vezes contrapostas. Até a década de 30 , a briga contra os acadêmicos uniu modernistas de orientações diferentes. 0 Salão de Belas Artes realizado no Rio em 1931, por exemplo, reuniu Ismael Nery (1900-1934), Cícero Dias (1907-2003), V. Brecheret (1894-1955), Tarsila do Amaral (1886-1973), Anita Malfatti, Alberto da V. Guignard (1896-1962) e Portinari - um elenco subversivo que ocupava, assim, a casa do academicismo, o que custou a Lúcio Costa (1902-1998) seu cargo na instituição. ${ }^{3}$ Não demorou para que esses mesmos artistas se deslocassem para campos distintos, representados pelo grupo dos figurativos e dos abstratos. As terapias artísticas com doentes mentais, possibilitadas por iniciativas como a de Nise da Silveira (1905-1999) no Centro Psiquiátrico de Engenho de Dentro a partir de 1946 no Rio, assim como a escola de arte para crianças aberta por Augusto Rodrigues (1913-1993) em 1948 e as aulas ministradas para o público infantil por Ivan Serpa (1923-1973) a partir de 1952, enfatizaram o poder espontâneo da formalização artística, independentemente da atenção temática ou política que havia 
animado o primeiro modernismo, e que encontrara em Di Cavalcanti (1897-1976) e Cândido Portinari (1903-1962) seus principais expoentes. Formando-se em um repertório diverso, os artistas abstratos terminaram encontrando respaldo nas instituições do circuito, como registra Otília Arantes. A II Exposição Francesa (1945); a criação, no fim da década de 1940, dos museus de arte moderna do Rio e de São Paulo (que teve como primeiro diretor Léon Dégand, expoente do abstracionismo francês) e do MASP; a exposição de Max Bill (1950) e, por fim, as bienais de São Paulo "acabaram de mudar a mentalidade reinante, a tal ponto que, na década de 1950, a abstração será a tendência dominante da arte brasileira" ${ }^{4} \mathrm{~A}$ partição do prêmio de pintura da Bienal de 1953 entre Di Cavalcanti e A. Volpi (1896-1988) atesta a coexistência - não exatamente pacífica - entre partidários de uma arte figurativa com temática nacional e partidários da abstração. ${ }^{5}$ Mas não só: atesta também a cristalização institucional de poéticas divergentes, igualmente mediadas pela crítica e por um público que, por conta das polêmicas que movimentaram o circuito artístico, se descobria apto a sintonizar o que julgava ser relevante no panorama internacional, sem deixar de atinar para o que essa ou aquela escolha poética poderia implicar para a produção local. Algo como um circuito artístico estruturado surgia entre nós.

Além do dinheiro e atuação de gente como Ciccillo Matarazzo, a crítica desempenhou nessa história um papel decisivo. Mário Pedrosa - que, como observou L. C. Osório, via nas contribuições difundidas pela grande mídia uma alavanca para influir sobre grandes instituições como a Bienal de São Paulo ou dos museus de arte moderna do Rio e de São Paulo ${ }^{6}-$ esteve à frente dessa atualização. Foi ele o principal promotor de artistas ligados à arte abstrata, tais como Volpi, Ivan Serpa, Abraham Palatnik (1928-2020) e Cícero Dias. Refazendo a trajetória de Pedrosa, Otília Arantes aponta como a renovação do circuito artístico brasileiro precisou romper com a tradição do primeiro modernismo, para acolher as tendências ligadas ao neoconstrutivismo. ${ }^{7}$ Seria difícil conceber essa mudança do circuito negligenciando o papel exercido pela crítica, quer 
através das contribuições na imprensa, quer da atuação curatorial em instituições reconhecidas - um fenômeno que se repetiu nos lances seguintes, que remodelaram o circuito artístico brasileiro nos anos de 1950 e 1960. A primeira exposição do Grupo Frente, liderado por Ivan Serpa em 1954 no Rio - e que reunia, dentre outros artistas, Lygia Clark (19201988) e Lygia Pape (1927-2004) -, foi apresentada por Ferreira Gullar (1930-2016); a segunda, realizada em 1955 e que reuniu no MAM/RJ novos integrantes ao grupo, como Hélio Oiticica (1937-1980), foi encabeçada por Mário Pedrosa. A leitura sui generis que Gullar efetuou da fenomenologia de Merleau-Ponty foi decisiva para que, no "Manifesto Neoconcreto" (1959), ele atacasse o "racionalismo" e "o objetivismo mecanicista" dos concretistas de São Paulo. Também é preciso ter em conta esse empuxo e adensamento crítico para explicar o alcance dos textos de Ronaldo Brito no Opinião na primeira década dos anos de 1970, nos quais pôs à luz as articulações entre as manifestações artísticas e culturais locais e o contexto internacional. Sem esse tipo de reflexão, não teria sido possível efetuar qualquer "reavaliação de nossa tradição moderna" ou situar-se com discernimento e inventividade diante das poéticas em curso. $^{8}$

\section{3. (Curto-)Circuito em Curitiba nas décadas de 60 e 70}

Como essas questões se colocaram em Curitiba e no Paraná? A primeira impressão é de que se trata de um ambiente rarefeito, se comparado a outras regiões do país. Impressão que vem de longe e ultrapassa o domínio das artes visuais. No início dos anos de 1930, Brasil Pinheiro Machado (1907-1977) queixava-se da falta de expressão literária do estado, no seu entender formado por uma "retaguarda característica de incaracterísticos". ${ }^{9}$ Diagnóstico muito severo? Já se estava quase na década de 1950, e a primeira geração do modernismo literário já havia cedido espaço para nomes como Murilo Mendes, João Cabral, Lins do Rego, Érico Veríssimo, Jorge Amado, dentre outros, quando Dalton Trevisan se engajou, no Joaquim (fundado em 1946), numa luta feroz contra... o 
simbolismo! Apesar da hora, a ruptura veio a calhar, acenando para a "constituição de um campo literário algo mais avançado" na capital do estado. ${ }^{10}$ Mas nem tanto, ao menos a julgar pelas impressões do poeta paranaense de maior renome na segunda metade do século XX. Numa entrevista de 1978, Paulo Leminski afirma que, além do movimento simbolista (1890-1910), e à exceção de Dalton Trevisan, o Paraná "não produziu mais nenhum momento interessante". ${ }^{11} 0$ traço comum com as gerações antecedentes teria sido a constatação de uma descontinuidade permanente, o reconhecimento da ausência de uma história literária local que dialogasse com as demais contribuições da literatura nacional. Fernando Gil identifica, quase como a contrapartida desse sentimento de ausência, o forte anseio de abraçar de algum modo a cena contemporânea, "uma compulsão à contemporaneidade". ${ }^{12}$

No campo das artes plásticas propriamente ditas, a situação não foi muito diferente. Foi preciso aguardar o fim dos anos de 1950 para que o circuito artístico curitibano travasse contato mais efetivo com aquelas poéticas modernas que, no Rio e em São Paulo, já tinham sido absorvidas há mais de uma década pela crítica e vinham sendo incorporadas no plano institucional pelas Bienais e pelos museus de arte moderna. Geraldo Leão de Camargo assinala ter sido preciso aguardar a edição de 1957 do Salão Paranaense de Belas Artes, fundado em 1944 nos moldes idealizados por discípulos de Alfredo Andersen (1869-1935), como Theodoro De Bona (1904-1990) e Raul Gomes (1889-1975), para que o circuito artístico local assimilasse as novas tendências nas artes visuais. Uma assimilação dialética, já que o que se passou, na verdade, foi uma exclusão. Um grupo de artistas simpatizantes das poéticas modernas, reunidos em torno da galeria Cocaco, dirigida por Ennio Marques Ferreira (1926), teve a maior parte de suas obras recusada pela comissão de seleção. ${ }^{13}$ Resolveram então retirar suas poucas obras selecionadas para expô-las numa sala separada da Biblioteca Pública do Paraná, com o nome de Salão dos Pré-Julgados. Nessa ocasião, as 
divergências entre modernos e acadêmicos torna-se conflito aberto - sem, todavia, infletir numa franca oposição:

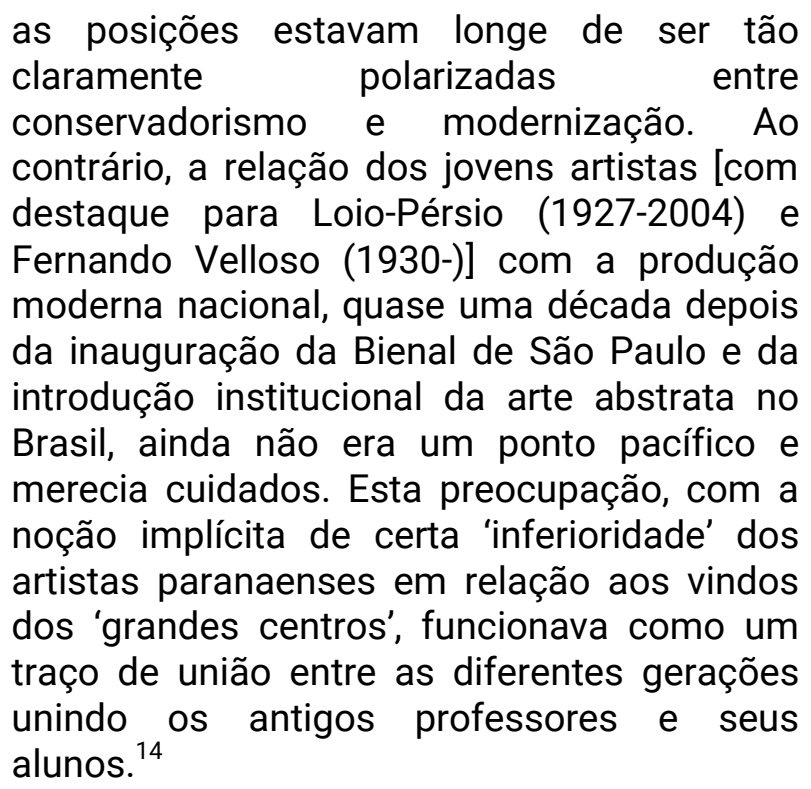

Outro fato ressaltado por Geraldo Leão ajuda a explicar essas reticências do meio artístico em relação às novas poéticas. No XVI Salão Paranaense (1959), foram extintos os "Prêmios de Aquisição", até ali promovidos pelos patrocinadores particulares do evento - prêmios que, como recordou Ennio Marques numa entrevista concedida em maio de 2001, por vezes superavam o orçamento anual do Departamento de Cultura do Estado. Habituados a adquirir obras acadêmicas, esses patrocinadores decidiram não apoiar os artistas que enveredavam pela abstração. A edição de 1960 do Salão, exprimindo tais idas e vindas, foi marcada por "premiações divididas entre tendências estranhamente conflitantes". ${ }^{15} 0$ maior prêmio ficou com uma escultura acadêmica de Oswaldo Lopes, secundado por uma escultura abstracionista de Paulo Gnecco (1926-1998).

Poder-se-ia cogitar que o episódio de 1960 reproduzia, em Curitiba, algo similar ao que se passara na Bienal de São Paulo de 1953, quando Di Cavalcanti e Volpi dividiram o primeiro prêmio de pintura. Mas há diferenças. Em São Paulo, os lados estavam bem demarcados; a divisão do prêmio correspondeu ao reconhecimento institucional da existência de duas frentes poéticas divergentes e claramente definidas. No Paraná, como 
aponta Geraldo Leão, embora os partidários das novas poéticas começassem a ganhar espaço na formulação das políticas culturais - no governo de Ney Braga (1961-1965), por exemplo, Ennio Marques se tornou diretor do Departamento de Cultura e, em colaboração com Eduardo Rocha Virmond, que dirigia o recém fundado Museu de Arte do Paraná, promoveu, em 1962, o "Salão do Paraná" (que aliás contou, dentre os jurados, com Mario Pedrosa) -, os artistas, de modo geral, não enveredaram pelo abstracionismo geométrico, pouco aceito tanto pelo público, quanto pelos grandes compradores e por parte da crítica local, que viu nas tendências neoconstrutivistas o descompromisso da arte com a representação da realidade social (retomando com isso um velho mote de Mário de Andrade). 0 balanço geral dos anos 50/60, assim, é, não tanto uma ruptura das novas poéticas com as anteriores, mas certo compromisso entre o velho e o novo. Nas palavras de Geraldo Leão:

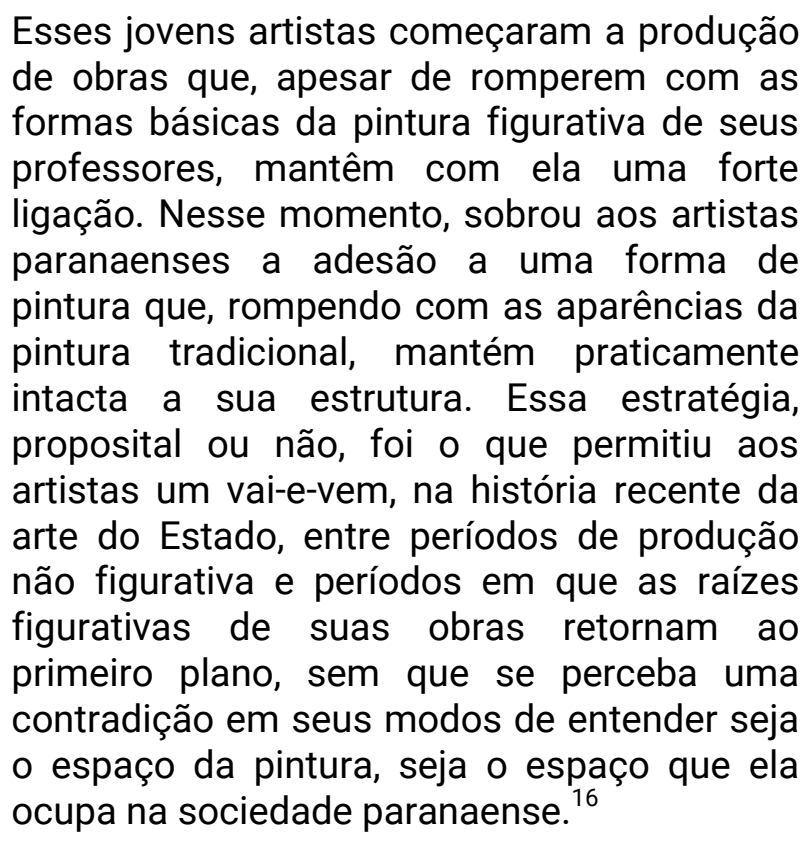

Digamos que a constelação do circuito artístico paranaense pelos idos de 1960, apesar de marcar a transição para sua estruturação sob o viés das poéticas modernas, deixou fios soltos para as gerações seguintes. É que, do ponto de vista moderno, soa estranho que artistas envolvidos na superação poética de opções formais tradicionais retornem a elas sem cerimônia, como se nada tivesse acontecido. Fernando 
Calderari, que protagonizou a ruptura com os discípulos de Andersen no início dos anos de 1960 e se tornou, nos anos seguintes, uma figura central para a constituição do circuito artístico moderno em Curitiba, intitulou assim a exposição de sua produção mais recente: "Vestígios de uma paisagem marinha. E por que não?" (2019). De fato, na falta de um circuito artístico moderno bem estruturado, de um cânone mediando valores, operando escolhas e exclusões, por que não voltar à paisagem - provavelmente o ponto forte da pintura local desde os tempos de Alfredo Andersen?

\section{A Mostra de Gravura de Curitiba}

Se quisermos arriscar um balanço, diremos que havia no circuito artístico de Curitiba por volta da década de 1960 um inegável anseio de renovação, só que atravessado por uma modernidade ambígua. As iniciativas eram muito dependentes da ação de figuras arrojadas, sem, contudo, dispor de enraizamento sólido junto ao público ou à clientela. Uma modernidade frágil, portanto - o que, para além de Curitiba e do âmbito das artes visuais, talvez tenha algo a nos dizer sobre a modernização à brasileira. Eis a pista de como a Bienal de Arte de Curitiba vai entrar nesta história, na narrativa de um acúmulo crítico e poético impersistente até, pelo menos, a década de 1970, e cujo drama Leminski, na frente literária, personificara com sua lucidez de faixa preta nas noites frias da capital paranaense. Antes de chegar ao assunto, duas palavras sobre 0 que se passou antes disso - o que nos leva à geração de 1980, quando as coisas começaram a mudar.

Durante os anos de 1970, com Fernando Velloso, Ennio Marques, Calderari e Virmond atuando junto a órgãos públicos voltados para a política cultural, a virada ensaiada nos anos anteriores deslanchou. Adelice Araújo, importante historiadora das artes visuais no Paraná, comenta ter vivenciado à época uma verdadeira "ditadura da abstração". ${ }^{17}$ Ennio Marques e Virmond também apareceriam, juntos com Fernando Calderari, na liderança disso que, antes da Bienal de Arte de Curitiba, foi o 
evento mais notório na história recente das artes visuais do Paraná: a Mostra de Gravura de Curitiba.

O projeto remonta ao fim dos anos de 1960, quando Ennio Marques e Calderari, aproximando-se de gravuristas ligados ao MAM/RJ, alentaram realizar a primeira mostra especializada em gravura em âmbito nacional. ${ }^{18} \mathrm{~A}$ ideia tornou-se realidade em 1978, com o apoio institucional da Fundação Cultural de Curitiba e da Funarte. Na sua primeira edição, Ennio Marques coordenou a premiação e Virmond integrou o júri. Como registra Artur Freitas, muitos dos artistas premiados em 1978 eram ligados à gravura carioca, "o que não só demonstrava uma certa convergência poética, como evidenciava um círculo de relações que sem dúvida passava pela mediação de Fernando Calderari e Ennio Marques, que, nos anos 1960, haviam iniciado um contato direto com o MAM do Rio". ${ }^{19}$ No Seminário realizado durante a Mostra, foram formuladas propostas em termos de um abaixo-assinado - no qual, além de pleitearem a realização anual do evento, os subscritos também solicitavam a realização conjunta "de um encontro de artistas, gravadores e críticos e demais interessados", além da formação de um acervo a partir das doações recebidas para a constituição de um Museu de Gravura em Curitiba. ${ }^{20}$ A Fundação Cultural acolheu as demandas. 0 apoio dos órgãos ao projeto confirmava-se pelo fato de que seus idealizadores permaneceram presentes na coordenação do evento até, pelo menos, 1982. Na segunda edição, inaugurada em dezembro de 1979, Calderari integrou a comissão de premiação. Virmond e Ennio Marques aparecem na terceira edição (novembro/dezembro de 1980; a primeira realizada no Solar do Barão), ambos numa Comissão de Premiação mais ampliada. $\mathrm{Na}$ quarta edição (setembro/outubro de 1981), ficaram responsáveis pela organização da premiação Lívio Abramo e Violeta Franco. Carlos Scliar, Constantino Viario, Danúbio Gonçalves e Fayga Ostrower compuseram o júri da quinta edição (setembro/outubro de 1982). Após a sexta edição, em 1984, o evento torna-se bienal: a sétima mostra, em 1986, incorporou na composição do júri artistas de Curitiba da nova geração, como Eliane Prolik. A última edição do evento, a 12a 
Mostra (1999), teve curadoria de Adriano Pedrosa, Lisette Lagnado e Paulo Reis, crítico de arte da cidade.

0 prestígio dos membros dos júris e o apoio dos órgãos públicos - implementando oficinas permanentes de gravura no Solar do Barão, que havia se tornado sede da Mostra e do Museu da Gravura desde 1983 -, o entrosamento entre artistas locais e de fora da cidade, assim como a categoria dos artistas selecionados ${ }^{21}$ - fez com que Curitiba realizasse por anos a fio aquele que virou o principal evento da gravura nacional. É nesta constelação mais arejada que um circuito artístico vai se tornando, no curso dos anos de 1980, mais diversificado, complexo e estruturado. A criação da Associação Profissional de Artistas Plásticos do Paraná (APAP-PR), em 21 de maio de 1983, e a abertura de galerias como a Casa da Imagem (1991) e Ybakatu (1995) acenam para esse amadurecimento. ${ }^{22}$ Através da APAP-PR, artistas atuantes na cidade durante a primeira metade dos anos de 1980 - muitos deles reunidos em grupos como Caixa de Bicho, Grupo Bicicleta, Grupo Moto Contínuo, Grupo PH4, Grupo Sensibilizar ${ }^{23}$ - passaram a integrar conselhos e comissões relevantes para as políticas visuais, incentivando a maior proximidade das novas poéticas com o público, fosse através da atuação em institutos como o Centro de Criatividade de Curitiba (criado uma década antes, em dezembro de 1973), fosse através de performances e happenings balizados pelas experiências do neoconcretismo. A Mostra de Gravura e a trajetória que conduziu a ela fortaleceram essas iniciativas, que, de seu lado, também reforçavam as edições do evento.

\section{Nosso assunto, finalmente}

Ao menos nas suas três primeiras edições, quando ainda levava seu nome de batismo - "Integração do Cone Sul: Mostra de Artes Plásticas" (1993) e, em seguida, "VentoSul: 2a Mostra de Artes Visuais Integração do Cone Sul" (1994) e "VentoSul: 3a Mostra de Artes Visuais Integração do Cone Sul" (1996) - a Bienal de Arte de Curitiba trilhou uma via completamente alheia ao caldo que vinha se formando na capital. 0 motivo é simples: 
as três primeiras edições simplesmente aconteceram muito longe de lá. Seu idealizador, Luiz Ernesto Meyer Pereira, desenhou o evento quando era secretário municipal da Cultura de Cascavel, na região oeste do Paraná, a 499 kms de Curitiba. ${ }^{24} \mathrm{~A}$ questão geográfica nem seria tão relevante, não fosse pela posição de Cascavel no mapa do Paraná. Com efeito, o evento foi pensado de início como integração do Brasil com Argentina, Chile, Paraguai e Uruguai, países do MERCOSUL. $O$ intuito de conferir ao bloco econômico seu lado cultural - algo que sempre lhe fizera falta ${ }^{25}$ - foi decisivo, quer para a captação de recursos, quer na seleção dos artistas. E também explica a composição da curadoria desde que o evento ganha envergadura, a partir de sua segunda edição (1994): Ticio Escobar (Paraguai), Adalice Araújo (Curitiba, Brasil), Fernando Cocchiarale (Rio de Janeiro, Brasil), Laura Buccellato (Argentina), Alice Haber (Uruguai), Nelly Richard (Chile) e Osvaldo Salerno (Paraguai). ${ }^{26}$ Isso também explica por que o evento também tenha realizado exposições no Palácio da Cultura Gustavo Capanema, no Rio; no Palácio do Itamaraty, em Brasília; e em Assunção, no Paraguai. Curitiba só entrou com uma exposição no Museu de Arte Contemporânea (MAC/PR). A terceira edição, aprofundando essa linha, contou com o apoio do Ministério das Relações Exteriores e teve como patrocinadores o Minc e o Banestado, encorpando a proposta original de integração de artistas brasileiros com artistas sulamericanos. Não surpreende que a Mostra VentoSul não criasse, de partida, vínculos com o que ia se passando no circuito artístico curitibano. Mesmo tendo reunido (especialmente em 1994 e 1996) ao conjunto de artistas de renome nacional e internacional alguns artistas do Paraná e de sua capital, o foco simplesmente era outro.

Mas o que acontece, quando, após uma interrupção de mais de dez anos, o evento transfere sua sede principal para a capital paranaense, em 2007? Os curadores dessa primeira edição em Curitiba (intitulada "4a Mostra Latino-Americana de Artes Visuais VentoSul", com sede na Casa Andrade Muricy) são Fábio Magalhães, Ticio Escobar e Fernando Cocchiarale - um paulista, um paraguaio e um carioca. A $5^{a}$ edição ("Bienal 
VentoSul", 2009) mantém o mesmo perfil da curadoria principal. Leonor Amarante, formada na FAAP/SP, havia sido dois anos antes a curadora da I Bienal do Fim do Mundo (2007), em Ushuaia, e, antes disso, curadora das segunda e terceira edições da Bienal do MERCOSUL (Porto Alegre, 1999/2001), em dobradinha com Fábio Magalhães. 0 evento permanece tendo como alvo a produção dos países integrantes do MERCOSUL. Há um fato novo: a Bienal passa a ocupar vários aparelhos culturais da capital, com exposições simultâneas no MAC/PR, no Museu da Gravura, no Museu Alfredo Andersen, no Museu da Fotografia da Cidade de Curitiba, no Museu de Artes da UFPR e no Memorial de Curitiba. A área de cobertura da Bienal na cidade expande-se vertiginosamente. No entanto, o interesse curatorial permanece sendo o Cone Sul. Curitiba apresenta-se como o meio para conferir maior projeção a um evento que, embora sediado na cidade, é voltado principalmente para fora. Curitiba torna-se cenário de uma megaexposição sem enraizamento autêntico com o circuito artístico local.

As coisas começam a assumir outro aspecto em 2011, ano em que o Museu Oscar Niemeyer se torna a sede principal da "VentoSul: Bienal de Curitiba 6". A comissão de curadoria, encabeçada por Alfons Hug (curador principal da Bienal de São Paulo em 2004 e 2006), inclui agora Eliane Prolik, Simone Landal, Artur Freitas e Denise Bandeira (esta como responsável pelo projeto arte/educação), todos artistas e críticos oriundos do circuito artístico de Curitiba. Juntos com eles figuram também José Alberto Saraiva (amazonense radicado no Rio e que havia sido co-curador da $2^{\text {a }}$ Bienal do Fim do Mundo em 2007) e, mais uma vez, Ticio Escobar. A ação educativa fica sob responsabilidade de Sonia Vasconcelos e Aline Bandeira, ambas professoras da Faculdade de Artes do Paraná (FAP/PR). Como afirmou à época Simone Landal, coube a ela, Artur Freitas e Eliane Prolik realizarem a mediação com a cena artística local. Mas, pelo que se depreende do seu depoimento, a mediação não foi nada simples. A começar porque Alfons Hug e Ticio Escobar, assessorados por Guevara (chilena que então morava na Alemanha) e Adriana Almada (argentina 
residente no Paraguai), tinham a palavra final sobre os selecionados. Já não bastasse esse "olhar bastante estrangeiro", seguiu-se também uma divisão curiosa de trabalhos: enquanto José Alberto Saraiva triava as obras brasileiras, o grupo de curadores locais ficava responsável pela representação curitibana - sujeita, como mencionado, à aprovação da curadoria geral. ${ }^{27}$ As obras de Curitiba seriam, então, menos brasileiras do que as do Rio Grande do Sul, de Minas, São Paulo ou Rio? Sem querer, retomava-se a mesma lógica que presidira o circuito artístico na cidade durante a década de 1960, quando, para ficarmos com um único exemplo, o II Salão Anual de Curitiba (promovido em 1961 pelo Museu Paranaense de Arte) distribuiu prêmios diferentes para o melhor artista brasileiro e para o melhor artista paranaense. ${ }^{28}$ Quando coisas difíceis de explicar se repetem, pode apostar, elas fazem sentido.

Lembra-se da observação de Geraldo Leão de que, durante os anos de 1960, um sentimento de subordinação marcou a relação dos artistas curitibanos com os artistas dos grandes centros? No seu entender, isso explicaria a união entre artistas de diferentes gerações na cidade - fator que impediu que se consumasse verdadeira ruptura com as poéticas mais tradicionais. ${ }^{29}$ Pelo que se depreende do relato de Simone Landal, cinquenta anos depois, um sentimento parecido reencontrou circunstâncias favoráveis para disseminar-se. Era como se aqueles fios que haviam produzido curto-circuito nos anos de 1960 e que tinham sido pouco a pouco remendados nos anos de 1980 se vissem outra vez desencapados - já que, como observa Simone na mesma entrevista, a partição curatorial que foi instituída na Bienal de 2011 fez com que se concebesse "Paraná e Brasil em instâncias distintas, não se pensa o todo". Com este agravante: aquela "compulsão à contemporaneidade", que, na trilha aberta por Fernando Gil para - campo literário, apontei aqui como contrapartida da impersistência do circuito artístico moderno em Curitiba, reunia agora plenas condições para realizar-se. 
A estruturação do circuito artístico local depende de fatores diversos, que vão além da existência de uma grande mostra. Seja como for, é difícil afirmar que a Bienal tenha fortalecido de algum modo esse circuito. A trajetória seguida pelo evento depois de 2011 não dá sinais manifestos nesta direção. A edição de 2013 (ano em que cai o nome "VentoSul") teve curadoria principal de Ticio Escobar e Teixeira Coelho, e como curadora adjunta Adriana Almada. Participou da curadoria também o artista performático curitibano Fernando Ribeiro. A edição, apoiada pela Fundação Cultural e pelo Banco Itaú, reuniu mais de 150 artistas dos cinco continentes e mobilizou mais de cem espaços da cidade. Ela também marcou a primeira edição do "Festival Internacional de Cinema Bienal de Curitiba", que se repetiria com sucesso nos anos seguintes. Em seguida, veio o susto. A Bienal de Curitiba 2015: "Luz do mundo" captou menos do que o esperado. No bojo da grande crise econômica que assolou o país, vieram os cortes orçamentários, levando a direção do evento a repensar seus rumos. Na edição seguinte, intitulada 'Bienal de Curitiba 17': China - país homenageado", o evento contou com o patrocínio de empresas estrangeiras, de gigantes chinesas como a Huawei e Buid Your Dreams, e há motivos para crer que toda a participação da China tenha sido bancada pela "China Arts and Entertainement Group" (CAEG), ligada ao Ministério da Cultura chinês. ${ }^{30} \mathrm{O}$ resultado foi uma Bienal praticamente cindida em duas mostras principais, ambas sediadas pelo Museu Oscar Niemayer: "Vibrações", com quase 250 obras escolhidas pelo Ministério de Cultura da China, e "Além da Fotografia", mostra organizada por Ticio Escobar com artistas dos países do Cone Sul. A divisão da curadoria em duas partes exteriores uma à outra alterou o equilíbrio existente até ali, marcado pela forte atuação (desde os primórdios em Cascavel) de Tício Escobar na escolha dos artistas. O eixo da captação dos recursos exigidos pela realização da mostra havia se deslocado, deixando de ser o MERCOSUL para tornar-se o BRIC, no interior do qual a China, como se sabe, exerce uma indiscutível preponderância. Tais mudanças, porém, não afetaram a relação da Bienal com o circuito local, que continuou sendo furtiva. A 
exceção é representada pelo Circuito Universitário da Bienal Internacional de Curitiba (CUBIC), criado em 2013 pela iniciativa de Stephanie Dahn Batista, do Departamento de Artes da Universidade Federal do Paraná. Voltada para jovens artistas, o CUBIC ocorre sob o guarda-chuva da Bienal e, numa escala reduzida, mas relevante, tem contribuído para estruturar o circuito artístico. Ao selecionar artistas de Curitiba e do Paraná sem perder de vista o diálogo com os artistas de outras regiões, igualmente recrutados para a mostra, o CUBIC exerce e institui parâmetros críticos exigidos para o adensamento da produção local. Mas a mostra não é apoiada financeiramente pela direção do evento, o que vai de par com a uberização que assola por todos os lados as formas de trabalho nos dias de hoje. Com efeito, a remuneração dos artistas, curadores e críticos envolvidos no CUBIC consiste em terem seus nomes escritos no catálogo da megaexposição.

\section{Considerações finais}

A realização de um evento do porte da Bienal de Curitiba em um país como o Brasil é uma façanha. Ao longo de sua trajetória, o evento produziu resultados significativos. Desde a criação do Museu de Arte de Cascavel, quando ainda não havia se tornado Bienal de Curitiba, passando pela consolidação do festival de cinema, mas, sobretudo, pelo número de artistas e países representados na mostra, assim como o de visitantes que pôs em contato com as artes visuais ao longo desses anos, a Bienal de Curitiba possui ganhos inegáveis.

Mas a pergunta aqui era outra. A questão era saber como a realização da Bienal de Curitiba incide, se é que incide, sobre o circuito artístico local. Apesar da presença de artistas da cidade na mostra, o apanhado feito aqui fez aumentar as dúvidas acerca da existência de algum tipo de articulação orgânica com eles. Pior, nada sinaliza mudança à vista. Vimos agora mesmo: até 2015, o foco do evento era o MERCOSUL; nas edições de 2017 e de 2019, passou a ser o BRIC. É natural esperar que a direção do evento busque recursos, lá onde eles estão disponíveis. Mas não há como ignorar as consequências 
que o soft power produz no circuito artístico contemporâneo. Por que o Ministério de Cultura chinês iria promover pontes entre a Bienal de Curitiba e o circuito artístico local? Isso é tarefa dos curadores e diretores do evento - desde que entendam que isso deva ser feito. $E$ podem perfeitamente entender que não é o caso, que isso seja uma questão antiquada. Talvez o problema todo esteja na pressuposição que terminei assumindo aqui, conforme a qual é válido discutir arte e circuito artístico sob a mesma perspectiva que orientou a crítica de Mario Pedrosa - uma pressuposição demasiado moderna. Sim, pensando bem, pode simplesmente ter acontecido que o léxico subjacente ao meu argumento "formação", "adensamento crítico", "cânone", "organicidade", etc. -, embora se case bem com as vanguardas artísticas e sua atualização em países periféricos, como o Brasil, tenha há algum tempo se tornado extemporâneo. $E$ isso não só para o caso discutido aqui, mas também para a Bienal de São Paulo e demais eventos desse porte. ${ }^{31} \mathrm{~A}$ particularidade da Bienal de Curitiba residiria, então, em já ter nascido contemporânea, sem jamais ter sido moderna. Não deixa de ser uma forma de vanguardismo.

De fato, muitas coisas mudaram. Viu-se como a estruturação do campo artístico curitibano entre os anos de 1960 e 1990 contou com o forte apoio de políticas públicas da cidade e do Estado do Paraná. Hoje, que as atribuições da Secretaria de Estado da Cultura foram transferidas para a nova Secretaria de Comunicação Social e da Cultura, a gestão estadual destina à cultura apenas $0,18 \%$ do orçamento (o previsto por lei é $1,5 \%$ ). ${ }^{32}$ A julgar pelo alcance das recentes iniciativas da Fundação Cultural de Curitiba, no município a situação não é melhor. Não fui ensinado a terminar artigos arrolando números, mas esses são bons: eles sugerem incluir naquele breviário lexical moderno a palavra "Estado". Na falta dele, não era de esperar que a configuração moderna do circuito artístico local sentisse - golpe, titubeasse? Eis aí um nexo promissor a ser desenvolvido: possivelmente a trajetória do circuito artístico de Curitiba ensine algo acerca das dificuldades de ser moderno sem Estado no Brasil. Ou melhor, mais ou menos sem Estado, 
visto que grande parte dos recursos para esses megaeventos provêm de leis de incentivo baseadas em renúncia fiscal. Mas isso é outra história. Por ora, a conclusão termina com esta suspeita: talvez a Bienal de Arte de Curitiba esteja nos ensinando quais são as modalidades de relação que megaexposições contraem com o meio artístico local no horizonte contemporâneo. Elas podem recrutar seus agentes, recorrer a suas instituições (artistas, críticos, curadores, aparelhos culturais, recursos públicos), sem precisar fomentar sua estruturação. Um pouco como os autônomos vinculados aos aplicativos de entrega ou transporte, os artistas estão livres para se virar.

\section{Referências bibliográficas}

ARANTES, Otília. Mário Pedrosa: itinerário crítico. São Paulo: Cosac Naify, 2004.

BRASIL DE FATO. "Não há secretaria nem orçamento para a cultura no Paraná". Ana Carolina Caldas, 25.04.2019. Disponível em: $<$ https://www.brasildefatopr.com.br/2019/04/25/naoha-secretaria-nem-orcamento-para-a-cultura-no-parana>. Acesso em 02.05.2020.

BRITO, Ronaldo. Experiência crítica. São Paulo: Cosac Naify, 2006.

CAMARGO, Geraldo Leão V. "O Salão Paranaense de Belas Artes". In: SZWAKO, José E. L.; OLIVEIRA, Márcio de. (orgs.) Ensaios de sociologia e história intelectual do Paraná. Curitiba: UFPR, 2009, p. 179-191.

CHIARELLI, Tadeu. Um jeca nos vernissages. São Paulo: EDUSP, 1995.

FABBRINI, Ricardo Nascimento. "Para uma história da Bienal de São Paulo: da arte moderna à contemporânea". Revista USP, n. 52 (fevereiro/2002), p. 46-55.

FREITAS, Artur. "A invenção do Solar do Barão. A gravura brasileira em Curitiba". CLIO: Revista de pesquisa histórica, v. 31, n. 2 (2013), s/pag. 
GASSEN, Lilian Hollanda. "Dos cavaletes às metalúrgicas: uma análise geracional nos caminhos da arte em Curitiba". In: SZWAKO, José E. L.; OLIVEIRA, Márcio de. (orgs.) Ensaios de sociologia e história intelectual do Paraná. Curitiba: UFPR, 2009, p. 193-207.

GIL, Fernando Cerisária. "Notas sobre as aporias da literatura no Paraná (ou o porquê de a literatura do Paraná não ter a sua história)". In: SZWAKO, José E. L.; OLIVEIRA, Márcio de. (orgs.) Ensaios de sociologia e história intelectual do Paraná. Curitiba: UFPR, 2009, p. 139-151.

LANDAL, Simone. "Entrevista a Georgia G. Bueno". In: Revista Clichê (nov de 2011). Disponível em $<$ http://www.revistacliche.com.br/2011/11/6-\%C2\%AAbienal-vento-sul/>. Acesso em 30.01.2020.

MAGALHÃES, Fábio. "Os anos trinta e as artes plásticas". In: FERREIRA, Ilsa Kawall (org.). Do modernismo à Bienal. São Paulo: Catálogo do Museu de Arte Moderna de São Paulo, 1982 (s/p).

OSÓRIO, Luiz Camilo. Olhar à margem. São Paulo: SESI-SP Editora/Cosac Naify, 2016.

PEDROSA, Mario. Acadêmicos e modernos. Textos escolhidos III. Edição organizada por Otília Arantes. São Paulo: EdUSP, 2004.

PLURAL. "Em audiência, Cultura pede mais investimentos". Ana Justi, 25.04.2019. Disponível em $<$ https://www.plural.jor.br/noticias/cultura/emaudiencia-cultura-pede-mais-investimentos/>. Acesso em 02.05.2020.

SOUZA, Marco Aurélio de. O Paraná no Campeonato Nacional das Letras: Uma leitura do jornal Nicolau à luz dos problemas da história literária regional. Tese (Doutorado em Estudos Literários). UFPR, Curitiba, 2020.

SANTOS, Myrian Sepúlveda. "As megaexposições no Brasil: democratização ou banalização da arte?" Cadernos de Sociomuseologia, v. 19, n. 19 (2002), p. 83-114. 
SOARES, Maria S. A. "A diplomacia cultural no MERCOSUL". Revista Brasileira de Política Internacional, v. 51, n. 1 (Brasília), s/p.

VAZ, Adriana. Olhares e narrativas: público do Museu Oscar Niemeyer. Curitiba: Appris, 2016.

VENTOSUL. "Mostra de artes visuais integração do Cone Sul". In: Enciclopédia Itaú Cultural de Arte e Cultura Brasileiras. São Paulo: Itaú Cultural, 2020. Disponível em: <http://enciclopedia.itaucultural.org.br/evento263261/ve ntosul-mostra-de-artes-visuais-integracao-do-cone-sul-21994-cascavel-pr-centro-cultural-gilberto-mayer>. Acesso em 02.05.2020.

Vinicius Berlendis de Figueiredo é professor do Departamento de Filosofia da UFPR.

${ }^{1}$ CHIARELLI, 1995, p. 64.

${ }^{2}$ CHIARELLI, 1996, p. 54.

${ }^{3}$ MAGALHÃES, 1982.

${ }^{4}$ ARANTES, 2004, p. 60.

${ }^{5}$ A primeira Bienal de São Paulo (1951), observa Pedrosa em texto redigido para o catálogo da Exposição de Artistas Brasileiros no MAM do Rio, em abril 1952, teria representado um "marco divisório" nas artes plásticas brasileiras (PEDROSA, 2004, p. 242).

${ }^{6}$ OSÓRIO, 2016, p. 97-98.

7 "Quase todos, artistas e críticos, eram veteranos do modernismo que, a partir dos anos 30 , finalmente entrara na rotina mental do país. Defendiam portanto uma tradição, a tradição do modernismo. Sem dúvida a inventiva tensão inicial baixara, mas bem ou mal, relativamente integrado, o sistema da arte moderna funcionava no Brasil. Ora, não custa lembrar que o auge do modernismo fora nacionalista, e o segundo tempo, francamente social. Além do mais, declaradamente hostil à tentação abstrata, contra a qual Mário de Andrade prevenia Tarsila em Paris" (ARANTES, 2004, p. 62).

${ }^{8}$ OSÓRIO, 2016, p. 95. Quanto ao papel decisivo de Mario Pedrosa nesta formação, consulte-se o próprio Ronaldo Brito: ele "esteve quase sempre no vértice do processo de compreensão e assimilação que a arte brasileira empreendeu com relação aos conceitos e tendências produzidos pelos chamados centros culturais" (BRITO, 2006, p. 48).

\footnotetext{
${ }^{9}$ MACHADO apud GIL, 2009, p. 140.

${ }^{10}$ GIL, 2009, p. 147.

${ }^{11}$ LEMINSKI apud GIL, 2009, p. 149.
} 
${ }^{12}$ GIL, 2009, p. 150.

${ }^{13}$ CAMARGO, 2009, p. 179.

${ }^{14}$ CAMARGO, 2009, p. 180.

${ }^{15}$ CAMARGO, 2009, p. 182.

${ }^{16}$ CAMARGO, 2009, p. 189.

${ }^{17}$ ARAÚJO apud GASSEN, 2009, p. 199.

${ }^{18}$ FREITAS, 2013.

${ }^{19}$ FREITAS, 2013, p. 3.

${ }^{20}$ FREITAS, 2013, p. 4.

${ }^{21}$ Para se ter ideia do alcance nacional da Mostra, veja-se alguns dos artistas participantes de 1992: Amilcar de Castro, Antonio Dias, Antonio Henrique Amaral, Cildo Meireles, Claudio Mubarac, Hélio Oiticica, Iberê Camargo, Iole Freitas, Jac Leirner, José Resende, Lívio Abramo, Goeldi, Regina Silveira, Sérgio Fingermann, Tunga, Waltércio Caldas e Willys de Castro, dentre outros.

${ }^{22}$ GASSEN, 2009, p. 196-197.

${ }^{23}$ GASSEN, 2009, p. 196.

${ }^{24}$ Luiz Ernesto foi empossado em seu mandato na Secretário municipal de Cultura, Esporte e Turismo de Cascavel em janeiro de 1989. Foi vereador do município entre 1997 e 2000. Em janeiro de 2006, voltou a ser secretário municipal da Cultura, encabeçando o $1^{\circ}$ Festival de Cinema de Cascavel.

${ }^{25}$ Ver SOARES, 2008, que menciona, dentre as poucas iniciativas exitosas no período que antecede a consolidação da Bienal de Curitiba, a Bienal do MERCOSUL, realizada em Porto Alegre desde 1997 e que teve sua $11^{\text {a }}$ edição em 2018.

${ }^{26}$ Cf. VENTOSUL,2020.

27 "[...] como falei somos três curadores para essa função, indicar os paranaenses, nos reunimos e discutimos os pontos de vista que se tem sobre a arte, os artistas que traduzem essas idéias, que a gente convive, que acompanhamos, e teve uma apresentação de um número grande de artistas, entre vinte e trintas artistas que apresentamos para a curadoria geral, e em conversas com eles, quem acabou batendo o martelo de quais seriam escolhidos foram os curadores gerais" (LANDAL, 2011).

${ }^{28}$ Ver VAZ, 2016.

${ }^{29}$ Esse compromisso entre gerações, conclui-se daí, teria dificultado ou até impedido a formação de um cânone artístico genuinamente moderno. 0 mesmo, note-se, teria ocorrido na literatura paranaense no século passado, mas sob uma forma invertida, através da "negação completa do dado local" (SOUZA, 2020, p. 40 ss.) - representada, primeiro, pelo confronto direto de Dalton Trevisan com Emiliano Perneta e, em seguida, pelo desprezo do jovem Leminski (revisto adiante) em relação ao autor de $O$ vampiro e a polaquinha (1965). Se fôssemos hegelianos, diríamos que as mediações 
estruturantes transcorrem no intervalo entre as soluções de compromisso e a total negação dos opostos.

30 Tomo como base dessas considerações a pesquisa de Aline Luize Biernastki (que contribui neste dossiê) sobre a relevância da diplomacia cultural na Bienal de Curitiba e em eventos similares.

${ }^{31}$ A discussão das edições mais recentes da Bienal de São Paulo feita por Ricardo Fabbrini reverbera essa mudança: o que representam as megaexposições no contexto artístico da pós-vanguarda? (FABBRINI, 2002). Consulte-se também SANTOS, 2002, que discute com grande interesse e liberdade o significado das recentes megaexposições no Brasil.

${ }^{32}$ Ver PLURAL, 2019; BRASIL DE FATO, 2019. 